\title{
Effects of high-intensity aquatic exercises on bone mineral density in postmenopausal women with and without vertebral fractures
}

\section{Fernanda Cerveira Abuana Osorio Fronza ${ }^{1}$, Linda Denise Fernandes Moreira-Pfrimer ${ }^{2}$, Rodrigo Nolasco dos Santos ${ }^{2}$, Luzimar Raimundo Teixeira ${ }^{1}$,Diego Augusto Santos Silva ${ }^{3}$, Édio Luiz Petroski ${ }^{3}$}

\author{
${ }^{1}$ School of Physical Education and Sports, University of São Paulo, São Paulo, Brazil \\ ${ }^{2}$ Division of Endocrinology School of Medicine, Federal University of São Paulo, São Paulo, Brazil \\ ${ }^{3}$ Division of Physical Education, Federal University of Santa Catarina, São Paulo, Brazil
}

\section{Email address:}

fernandacerveira@yahoo.com(F. C. A. O. Fronza)

\section{To cite this article:}

Fernanda Cerveira Abuana Osorio Fronza, Linda Denise Fernandes Moreira-Pfrimer, Rodrigo Nolasco dos Santos, Luzimar Raimundo Teixeira,Diego Augusto Santos Silva, Édio Luiz Petroski. Effects of High-Intensity Aquatic Exercises on Bone Mineral Density in Postmenopausal Women with and without Vertebral Fractures. American Journal of Sports Science.

Vol. 1, No. 1, 2013, pp. 1-6. doi: 10.11648/j.ajss.20130101.11

\begin{abstract}
This prospective controlled study evaluated the efficacy of a high-intensity aquatic exercise program on the safety of vertebral parameters, anthropometry and physical fitness of 108 non exercising postmenopausal women with and without fractures. Participants were divided into intervention group $(\mathrm{IG}=64)$ and control group ( $\mathrm{DG}=44)$ assessed in a first evaluation and after 24 weeks of intervention, data about bone densitometry, morpheme try(fractures), anthropometry, physical fitness, number of falls and pain perception. IG with fractures after training showed better results than CG with fractures for bone mineral density and t-score of the femoral head $(\mathrm{p}<0.05)$. Following protocol, IG without fractures showed better results than CG without fractures in flexibility tests, spine extension strength, hip flexor strength, left and right handgrip strength, and decrease in the number of fall sand pain perception $(\mathrm{p}<0.05)$. IG without fractures also obtained better results for right handgrip strength and decreased pain perception in comparison to CG with fractures. High-intensity aquatic exercises contribute to decrease pain and number of falls, improve physical fitness, and increase bone mineral density in postmenopausal women with and without vertebral fractures, with better performance in relation to group not submitted to exercises for the parameters studied.
\end{abstract}

Keywords: Postmenopausal, Spine, Fracture, Exercises, Aquatic

\section{Introduction}

The Brazilian Census Bureau (IBGE) projections, according to 2000 Census estimated that in 2020, the elderly population in Brazil might be over 30 million and will account for $13 \%$ of the population. These numbers point to a higher proportion of women than men due to differences in life expectancy between sexes, as women live an average of eight years more than men (IBGE, 2002).

Elderly process determines some changes like estrogen deficiency and increased resorption, which are factors that determine bone loss in women. After menopause, women with estrogen deficiency undergo accelerated bone loss, particularly trabecular bone (5\% to $6 \%$ per year), and this process goes on for about 5 to 10 years after menopause (CASTRO et al, 2008).

Bone loss may reach pathological levels and be classified as osteoporosis, a skeletal disorder characterized by reduced bone mass; which may also compromise bone resistance and expose individuals to a higher risk of fractures (NATIONAL INSTITUTE OF HEALTH, 2001), the main consequence of osteoporosis.

Both men and women undergo a decline in mineral bone density (MBD) starting in middle age. Women have faster bone loss in the first years after menopause, which exposes them to greater risk of fractures (NIH, 2000). Fractures due to osteoporosis affect the spine, particularly the thoracic spine, hip (femur neck) and forearm (wrist) (NIH, 2000; BROWN and JOSSE, 2002; PINTO NETO et al., 2002; SMITS, ENGELSMAN et al., 2003). 
Loss of bone mass and muscle strength leads to a reduction in strength, force and muscle resistance, which exposes the elderly to greater risks of falls and fractures and greater difficulty in performing basic or complex daily activities (HUNTER et al., 2004).

The adaptation of exercise to obtain satisfactory osteogenic responses while preserving the locomotor system and cardiovascular health has been largely discussed in literature. According to Sinäki (2007), not all exercises are osteogenic as they affect bone and muscle differently. Bone formation depends on type, intensity and duration of the exercise performed. The function of exercises for individuals with osteoporosis is, therefore, to increase the competence of the neuromuscular structures and to reduce the risk of fractures (SINAKI, 2007; TOLOMIO et al., 2010). Pfeifer et al. (2004) concluded that interventions using exercises to strengthen back extensor muscles are beneficial in cases of spine fractures. They found that these exercises prevented the first consequences of osteoporosis, which are thoracic hyperkyphosis, spine fractures, height loss and chest pain.

The advantage of aquatic exercise is that compressive overloads on the spine in aquatic environments are low due to the physical properties of water (buoyancy) and the depth of the pool when there is no contact of feet with the floor (WILDER; BRENNAN, 2001). In such environments, exercise may have a high physiological load, but the external load is low. However, recent studies have demonstrated the importance of exercise in water to maintain discrete increases in the markers of bone formation and remodeling (AY and YURTKURAN, 2005), and the effect of aquatic exercise still in conclusive, requiring further studies. This study evaluated the efficacy of a high-intensity, 6month aquatic exercise program according to vertebral parameters, anthropometry and physical fitness of postmenopausal women with and without fractures

\section{Method}

This prospective controlled randomized study included 108 postmenopausal women aged 45 to 80 years who regularly visited the "Parque da Maturidade" in Baueri, Brazil.

The study was submitted to the Ethics Committee of UNIFESP (number 1711/10), and, after approval, the "Parque da Maturidade" visitors were invited to participate in it. Inclusion criteria were: 1) postmenopausal women not menstruating for at least 5 years; 2) inactive according to the short-form of the International Physical Activity Questionnaire (IPAQ-short);3) whose cognitive functions allowed them to understand and respond to commands used during physical evaluation.

Sample size was calculated according to muscle strength (main variable). The Graphpad State 2 software was used to calculate sample size, and results indicated that 25 volunteers should be included in each group for the sample to have a power of $99 \%$ to detect a difference of 4.38 between means at a significance level of 0.05 (alpha). As there were more volunteers than the number estimated, we decided to include them in the study to improve the precision of results.

The study began with 108 participants and finished with 92women. Volunteers were randomly divided into two groups: intervention group (IG), with 64participants, and control group (CG), with44, and within this distribution, there were women with or without vertebral fractures in both groups. Therefore, IG was divided into two subgroups: IG without fractures $(n=55)$ and IG with fractures $(\mathrm{n}=11)$. The $\mathrm{GC}$ was also divided into two subgroups: $\mathrm{CG}$ without fractures $(\mathrm{n}=33)$ and $\mathrm{CG}$ with fractures(n=9) (figure 1).

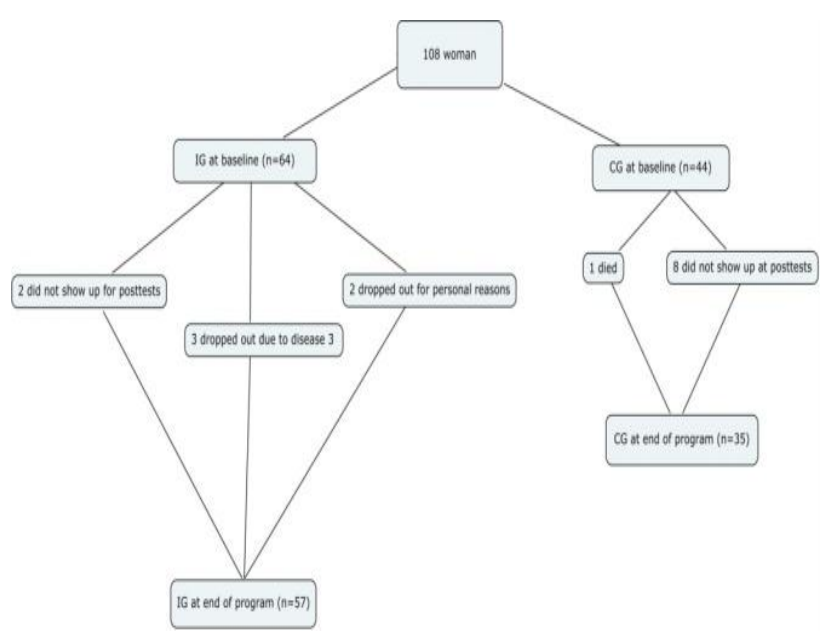

Figure 1: Study participant flowchart

All women enrolled in the study kept their normal diets, under medical supervision, and received oral daily diet supplementation with one capsule containing $500 \mathrm{mg}$ elemental calcium (calcium carbonate) and 1000 IU cholecalciferol (vitamin D3), to be taken after breakfast during 6 months of study. This supplementation was adopted in both groups so that all participants benefited from the effects of calcium and vitamin D, already described in literature (PEDROSA et al., 2005; MOREIRA-PFRIMER et al., 2009).

Evaluations carried out in the initial period and after 24weeks of intervention were:

1) Anthropometric measures (body mass and height). Body mass was assessed using a Filizola scale model 31(Brazil) with resolution of $0.1 \mathrm{~kg}$. Height was measured using a stadiometer, and body mass index (BMI) was calculated based on body weight and height values.

2) Physical fitness tests to assess flexibility, isometric strength of the hip flexor, knee extensor and spine extensor muscles. Flexibility was measured using the sit-and-reach test with a box (WELLS and DILLON,1952). Participants had to sit on a thin mattress on the ground, place the sole of their feet against the standard box and extend their legs. The participant flexed the trunk, and spine flexibility was recorded in centimeters. In standard bench during the tests, the participant's soles coincide with the $23 \mathrm{~cm}$ of measure tape (WELLS and DILLON, 1952).

Isometric strength of hip flexors, knee extensors and back extensors was tested using a portable mechanic dynamometer (Lafayette Manual Muscle Test System - Model 01163, Lafayette Instrument, Lafayette, IN). The test to assess the isometric force in accordance with the device's manual, 
recommends that the dynamometer should be positioned over the muscle to be tested, and the observer kept it there for 5 seconds against the resistance of the woman being tested. Maximum isometric strength was recorded as the mean of 3 measurements. The muscles tested in the lower limbs were chosen because they are directly associated with walking and the risk of falls, and also because the back extensors are involved in the quality of upright standing, and their weakness is associated with spine fractures. Sinäki et al.(2005) reported that patients with osteoporosis and thoracic hyperkyphosis have weaker spinextensor muscles, reduced strength in the lower limbs, slow gait, balance alteration with greater body sway, all resulting in predisposition to falls.

3) Number of falls reported by participants in the six months prior to protocol and during its application. During the monthly meetings for the delivery of supplementation by researchers, volunteers were asked about the occurrence of these events. The fall criterion adopted in this study was defined by Tideiksaar (2002) as "any event in which a person intentionally or inadvertently come to the ground or some lower level, such as a chair, toilet or bed".

4) Pain assessment using a visual analog scale (VAS) that quantifies the individual's level of pain on a scale from zero (no pain) to 10 (maximum pain experienced) reported by the individual (HUSKISSON, 1974).

5) Spine morphometry, used to detect spine fractures, was obtained from images acquired using dual-energy X-ray absorptiometry (DXA, Hologic, Discovery A model, QDR series). The form and consequent possible fracture were characterized using 6 points in each vertebral body: two anterior, two middle and two posterior points. Heights were compared. This study used a modified version of parameters described by GENANT et al. (1993), as well as the QDR and Physician Viewer (Hologic) software. To ensure greater clinical safety in detection, fractures were defined as reductions greater than $30 \%$ in comparison with initial vertebral height.

Tests to determine Bone Mineral Content (BMC) in grams, and BMD in $\mathrm{g} / \mathrm{cm}^{2}$, T-scores ofL1-L4, head, trochanter and femoral neck were performed using DXA (Hologic, Model Discovery A, series QDR) and analyzed using the Physicians Viewer software version 5.4 and QRD version 12.4 (Hologic). Bone mass evaluation was performed in the lumbar spine between L1 and L4, and the proximal femur (femoral neck, trochanter, inter trochanter and Ward's triangle) were also obtained by DXA device.

The aquatic exercise program lasted 24 weeks and had 3 sessions per week (Monday, Wednesday and Friday), which lasted $50 \mathrm{~min}$ each, on average. Sessions were divided into three parts: (1) warm-up, which lasted about 10 minutes and included joint and general warm-up and focused on muscles that would undergo dynamic strength work; (2) main part, which included specific dynamic force training, lasting 9, 13, 17 and 28 minutes for microcycles 1, 2, 3 and 4, and aerobic exercises at intensity of $80 \% \mathrm{Fcmax}$, controlled by using the Borg scale for subjective effort perception, lasting about 16, 13 and 9 minutes for microcycles 1, 2 and 3; (3) final part, which lasted 15 minutes and was designed for relaxation, with exercises for joint mobility, balance, proprioception and overall stretching.

During macrocycles, a sequence of exercises was kept in the main part of the muscle strength exercise session, composed of 3 groups of exercises each, and the speed increase was the overload. All exercises had the purpose of increasing strength of knee flexors and extensors, as well as of hip adductors and abductors. Spine extensors were exercised in directed movements during the aerobic part of the session.

The SPSS software 7.0 was used for descriptive statistic analysis and to characterize the sample according to the central tendency measures (means) and dispersion (standard deviation) of the profiles of IG (who practiced aquatic exercises) and CG.

The Kolmogorov-Smirnov test was used to test the normal distribution of data, and the null hypothesis of normal model adherence was accepted for $\mathrm{p}$ values greater than 0.05 . Descriptive statistics was used to characterize the sample, considering the measures of central tendency (mean) and dispersion (standard deviation) on the profiles of intervention and control groups. The percentage delta $(\Delta \%)$ between preand post-intervention periods for each variable investigated was calculated. Interaction between groups (IG and CG) and intervention period (Pre and Post) for dependent variables was observed, using the two-way analysis of variance (ANOVA). In all analyses, a significance level of $5 \%(\mathrm{p} \leq 0.05)$ was adopted. All analyses were performed with the aid of the SPSS statistical package, version 17.0.

\section{Results}

Table 1 shows a comparison of body weight, height and BMI between control and intervention groups in the pre- and post-intervention periods. In the pre-intervention period, no differences between groups with and without fractures were found. After the aquatic exercise program, no significant change in the weight, height and BMI values of groups investigated was found.

\begin{tabular}{|c|c|c|c|}
\hline Variables & $\begin{array}{c}\begin{array}{c}\text { Pre- } \\
\text { intervention }\end{array} \\
\text { Media M } \\
\text { (Standard } \\
\text { deviation } \\
\text { SD) } \\
\end{array}$ & $\begin{array}{c}\begin{array}{c}\text { Post- } \\
\text { intervention }\end{array} \\
\text { Media M } \\
\text { (Standard } \\
\text { deviation } \\
\text { SD) } \\
\end{array}$ & $\Delta \%$ \\
\hline Body weight (kg) & & & \\
\hline CG without fractures & $73.1(12.8)$ & $72.7(14.9)$ & -0.6 \\
\hline IG without fractures & $73.0(15.6)$ & $71.7(16.1)$ & -1.8 \\
\hline CG with fractures & $76.6(12.3)$ & $75.0(13.0)$ & -2.1 \\
\hline IG with fractures & $76.1(17.5)$ & $82.4(16.3)$ & 8.3 \\
\hline Height $(\mathbf{c m})$ & & & \\
\hline CG without fractures & $155.7(5.6)$ & $156.1(6.2)$ & 0.3 \\
\hline IG without fractures & $155.7(6.2)$ & $156.1(6.1)$ & 0.3 \\
\hline CG with fractures & $156.7(6.7)$ & $154.6(5.6)$ & -1.3 \\
\hline $\begin{array}{r}\text { IG with fractures } \\
\text { BMI }\left(\mathbf{k g} / \mathbf{m}^{2}\right)\end{array}$ & $157.8(4.6)$ & $158.8(3.6)$ & 0.6 \\
\hline CG without fractures & $30.1(4.1)$ & $28.9(4.3)$ & -4.0 \\
\hline IG without fractures & $30.0(5.8)$ & $29.4(5.8)$ & -2.0 \\
\hline CG with fractures & $32.0(3.8)$ & $31.7(4.6)$ & -0.9 \\
\hline IG with fractures & $30.4(6.1)$ & $32.7(6.5)$ & 7.6 \\
\hline
\end{tabular}




\begin{tabular}{|c|c|c|c|}
\hline Variables & $\begin{array}{c}\text { Pre- } \\
\text { intervention }\end{array}$ & $\begin{array}{c}\begin{array}{c}\text { Post- } \\
\text { intervention }\end{array} \\
\text { Media M } \\
\text { (Standard } \\
\text { deviation SD }\end{array}$ & $\Delta \%$ \\
\hline \multicolumn{4}{|l|}{ BMC-L1/L2 (g) } \\
\hline CG without fractures & $48.1(10.8)$ & $47.8(10.3)$ & -0.6 \\
\hline IG without fractures & $48.5(9.5)$ & $48.5(10.2)$ & 0.0 \\
\hline CG with fractures & $45.0(13.6)$ & $42.7(12.2)$ & -5.1 \\
\hline IG with fractures & $50.8(11.8)$ & $51.7(11.5)$ & 1.8 \\
\hline \multicolumn{4}{|l|}{ BMD - L1/L2 $\left(\mathrm{g} / \mathbf{c}^{2}\right)$} \\
\hline CG without fractures & $0.9(0.1)$ & $0.9(0.1)$ & 0.0 \\
\hline IG without fractures & $0.9(0.1)$ & $0.9(0.2)$ & 0.0 \\
\hline CG with fractures & $0.9(0.2)$ & $0.8(0.2)$ & -11.1 \\
\hline IG with fractures & $0.9(0.2)$ & $0.9(0.2)$ & 0.0 \\
\hline \multicolumn{4}{|l|}{ T-score - L1/L2 } \\
\hline CG without fractures & $-1.0(1.3)$ & $-1.2(1.2)$ & 20.0 \\
\hline IG without fractures & $-1.2(1.3)$ & $-1.3(1.4)$ & 8.3 \\
\hline CG with fractures & $-1.5(1.6)$ & $-1.8(1.6)$ & 20.0 \\
\hline IG with fractures & $-1.1(1.6)$ & $-1.1(1.5)$ & 0.0 \\
\hline \multicolumn{4}{|l|}{ BMC-femoral head (g) } \\
\hline CG without fractures & $3.8(0.6)$ & $3.8(0.6)$ & 0.0 \\
\hline IG without fractures & $3.8(0.6)$ & $3.9(0.7)$ & 2.6 \\
\hline CG with fractures & $3.8(0.9)$ & $3.5(0.8)$ & -7.9 \\
\hline IG with fractures & $4.0(0.9)$ & $4.1(0.8)$ & 2.5 \\
\hline \multicolumn{4}{|l|}{ BMD - femoral head $\left(\mathrm{g} / \mathrm{c}^{2}\right)$} \\
\hline CG without fractures & $0.8(0.1)$ & $0.8(0.1)$ & 0.0 \\
\hline IG without fractures & $0.8(0.1)$ & $0.8(0.1)$ & 0.0 \\
\hline CG with fractures & $0.8(0.2)$ & $0.7(0.1)$ & -12.5 \\
\hline IG with fractures & $0.9(0.1)$ & $0.9(0.1)^{*}$ & 0.0 \\
\hline \multicolumn{4}{|l|}{ T-score - femoral head } \\
\hline CG without fractures & $-0.3(0.9)$ & $-0.5(0.9)$ & 66.7 \\
\hline IG without fractures & $-0.3(1.3)$ & $-0.5(1.2)$ & 66.7 \\
\hline CG with fractures & $-0.5(1.8)$ & $-1.1(1.3)$ & 120.0 \\
\hline IG with fractures & $0.2(1.3)$ & $0.4(1.1)^{*}$ & 100.0 \\
\hline \multicolumn{4}{|l|}{ BMC-femoral trochanter (g) } \\
\hline CG without fractures & $7.0(1.1)$ & $7.1(1.2)$ & 1.4 \\
\hline IG without fractures & $6.6(1.3)$ & $6.7(1.3)$ & 1.5 \\
\hline CG with fractures & $7.0(1.9)$ & $6.9(2.0)$ & -1.4 \\
\hline IG with fractures & $7.4(1.2)$ & $7.1(1.3)$ & -4.1 \\
\hline \multicolumn{4}{|l|}{ BMD-femoral trochanter $\left(\mathrm{g} / \mathrm{c}^{2}\right)$} \\
\hline CG without fractures & $0.7(0.1)$ & $0.7(0.1)$ & 0.0 \\
\hline IG without fractures & $0.7(0.1)$ & $0.7(0.1)$ & 0.0 \\
\hline CG with fractures & $0.7(0.1)$ & $0.6(0.1)$ & -14.3 \\
\hline IG with fractures & $0.8(0.1)$ & $0.7(0.1)$ & -12.5 \\
\hline \multicolumn{4}{|l|}{ T-score - femoral trochanter } \\
\hline CG without fractures & $-0.1(0.7)$ & $-0.3(0.8)$ & 200.0 \\
\hline IG without fractures & $-0.3(1.2)$ & $-0.2(1.1)$ & -33.3 \\
\hline CG with fractures & $-0.3(1.4)$ & $-0.5(1.4)$ & 66.7 \\
\hline IG with fractures & $0.5(1.2)$ & $0.5(1.2)$ & 0.0 \\
\hline \multicolumn{4}{|l|}{ BMC - total femur (g) } \\
\hline CG without fractures & $28.8(4.7)$ & $28.6(4.1)$ & -0.7 \\
\hline IG without fractures & $27.4(5.1)$ & $27.6(5.2)$ & 0.7 \\
\hline CG with fractures & $27.3(7.4)$ & $26.3(7.2)$ & -3.7 \\
\hline IG with fractures & $30.6(6.7)$ & $29.9(5.5)$ & -2.3 \\
\hline \multicolumn{4}{|l|}{ BMD - total femur $\left(\mathrm{g} / \mathrm{c}^{2}\right)$} \\
\hline CG without fractures & $0.9(0.1)$ & $0.9(0.1)$ & 0.0 \\
\hline IG without fractures & $0.9(0.1)$ & $0.9(0.1)$ & 0.0 \\
\hline CG with fractures & $0.9(0.2)$ & $0.8(0.2)$ & -11.1 \\
\hline IG with fractures & $1.0(0.2)$ & $1.0(0.2)$ & 0.0 \\
\hline \multicolumn{4}{|l|}{ T-score - total femur } \\
\hline CG without fractures & $-0.1(0.7)$ & $-0.2(0.8)$ & 100.0 \\
\hline IG without fractures & $-0.4(1.1)$ & $-0.4(1.1)$ & 0.0 \\
\hline CG with fractures & $-0.5(1.6)$ & $-0.8(1.6)$ & 60.0 \\
\hline IG with fractures & $0.3(1.4)$ & $0.1(1.3)$ & -66.7 \\
\hline
\end{tabular}

Table 2 shows a comparison of bone content and mineral density between control and intervention groups in the pre- and post-intervention periods. In the pre-intervention period, no differences between intervention and control groups with and without fractures were observed ( $p>0.05$ ). After aquatic exercise program, IG with fractures showed higher BMD and Tscore values compared to $C G$ with fractures $(p \leq 0.05)$. For the other variables, BMD and BMC did not differ between intervention and control groups.

Table 3 shows the comparisons of components physical fitness, number of falls, pain points and visual analogue scale of pain between control and intervention groups in the pre- and post-intervention periods. At baseline, no differences between intervention and control groups with and without fractures were observed ( $p>0.05$ ). After the training period, IG without fractures showed higher flexibility, spine extension strength, hip flexor strength, right and left handgrip strength in relation to baseline values $(p \leq 0.05)$. In addition, after aquatic exercise program, IG without fractures showed a decrease in the number of falls and pain perception $(\mathrm{p} \leq 0.05)$. After 24 weeks of intervention, IG without fractures showed better results for spine extension strength and pain perception than CG without fractures $(\mathrm{p} \leq 0.05)$.

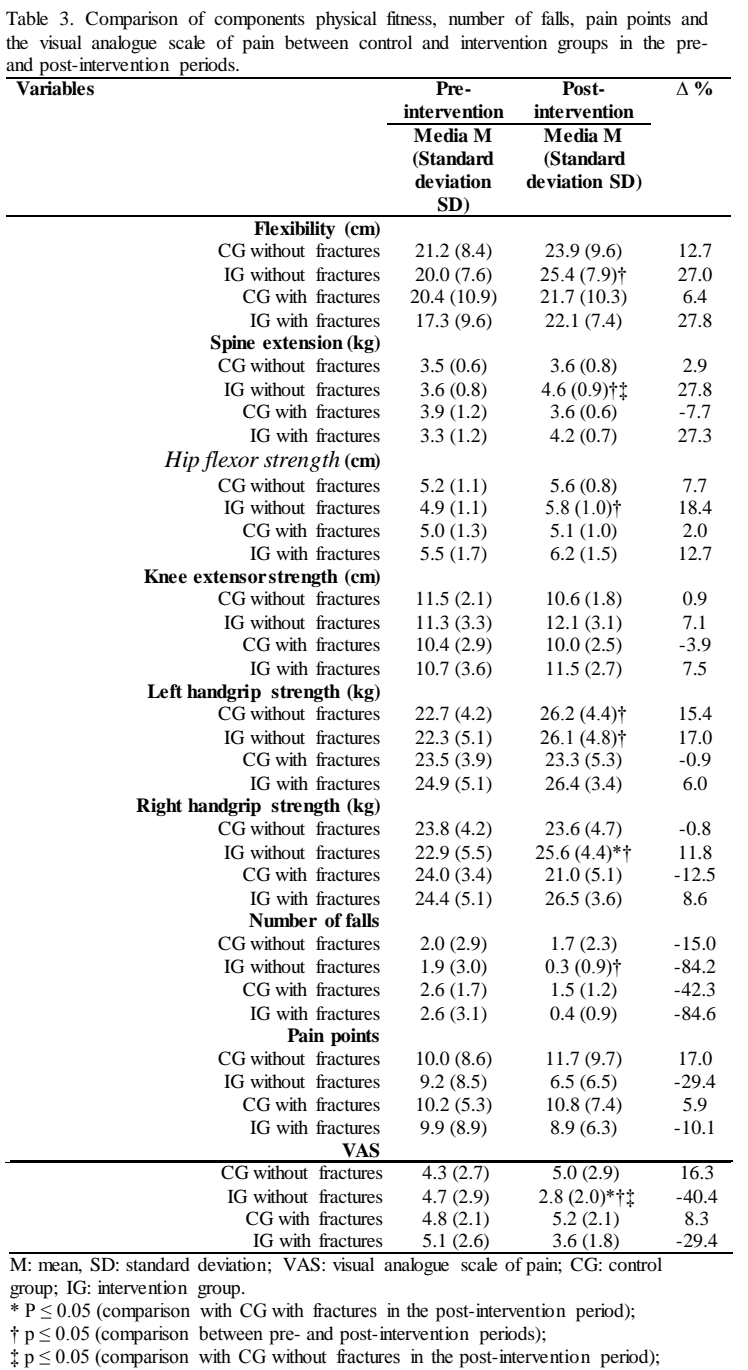

Moreover, IG without fractures showed better results for right handgrip strength and pain perception than CG with fracturein the post-intervention period $(p \leq 0.05)$. For the other variables, no significant differences between groups in the pre and postintervention periods were observed.

\section{Discussion}

When control and intervention groups are compared for variables body weight, height and BMI, no changes in the pre and post intervention periods were observed. A possible explanation for the lack of change in body mass is that although individuals were performing weekly physical activities, there was no diet control that would impact this variable (Kemmler et al. 2004), since they were instructed to keep the routine diet. About stature, no change was expected, given the space of 24 weeks of protocol application, similar to the study of Narciso et 
al. (2010), which compared the percentage height values in active and sedentary elderly of both sexes in a 12-month period and found no significant differences in pre- and post-test $(\mathrm{p}=$ 0.88 and $\mathrm{p}=0.68$, respectively). BMI, directly involved in both variables, did not change significantly due to the lack of changes in body mass.

When aspects related to bone mass were investigated, IG with fractures showed increases of BMD and T-score of the femoral head higher than values shown by CG with fractures $(\mathrm{p} \leq 0.05)$. This indicates that the high physiological intensity aquatic exercise protocol was effective as it increased the BMD of the femoral head for individuals with vertebral fractures, even under this spine condition, obtained better results for BMD than women who did not perform exercises. Exercises, in addition to slowing the natural age-related changes in bone structure in postmenopausal women, can result in increased cortical area and cortical BMD in long bones such as femur, and also slows the loss of trabecular bone in vertebrae (HAMILTON et all, 2010). According to Ay and Yurtkuran (2005), as long as it causes repeated mechanical loads in the long bones, aquatic exercise performed outside normal physiological range, is capable of producing significant increases in bone quality. Thus, data from this study corroborate studies by Tolomio et al. (2010), who also detected a significant improvement in bone mineral density of the femoral neck in women exercised both in soil and in water when compared to control group.

IG without fractures showed higher flexibility, spine extension strength, hip flexor strength and right and left handgrip strength values in relation to baseline, and decreased number of falls and pain perception. These findings are consistent with studies by Khazzani et al (2009), who highlighted that poor physical performance on fitness tests would be associated with lower BMD, and to a high risk of falls and fractures. The result obtained by the IG without fractures supports the importance of exercises for postmenopausal women (MIYAKOSHI et al., 2003; SINAKI et al., 2010) and also the better performance due to the lack of fractures.

Individuals with osteoporosis and kyphosis are more susceptible to vertebral fractures and show peculiarities in musculoskeletal aspects, with weaker spine extensor muscles, reduced strength in the lower limbs, slow gait, changed balance with greater body sway and susceptibility to falls (SINAKI et al. 2005). Moreover, vertebral fractures also unchain back pain, height loss, loss of function and reduced quality of life (SMITSENGELSMAN et al., 2003). These problems typical of individuals with vertebral fractures explain the difference in performance of the same group exercised with and without fractures, although no intergroup differences were observed (IG) at baseline.

Improvements were also detected after application of the aquatic exercise protocol for the IG without fractures for spine extension strength and pain perception compared with CG without fractures $(p \leq 0.05)$. This finding underscores the importance of physical exercises as a protective factor for the occurrence of fractures, in which the increase of strength in the spine extensors, which strengthen muscles, minimize the risk of fractures and reduce pain in the dorsal region and the level the perception of this pain (MIYAKOSHI et al., 2003). Thus, it is understood that one of the major factors for the occurrence of fractures, weakness of the spine extensor muscle group, was duly corrected with strengthening exercises worked with specific movements within the aquatic exercise protocol.

IG without fractures showed even better results for the right handgrip strength and pain perception when compared to CG with fractures in the post-intervention period. The importance of measuring handgrip strength is to provide an objective index of the functional integrity of the upper limbs, a result that indicates that vertebral fractures may be related to reduce strength in the upper limbs. Studies such as those by Dixon et al. (2005) reported that low handgrip strength in men and women may be associated with predisposition to vertebral fractures.

Pain perception was lower for IG without fractures when compared to CG with vertebral fractures. This result was expected because although vertebral fractures do not necessarily cause pain of sufficient magnitude to arouse the interest of patient or physician (LEWIECKI and LASTER, 2006), there are symptomatic fractures in women with osteoporosis that are significantly related to the deformity index (vertebral body height) (DOO, 2008). For this reason, women with fractures feel more pain than those without fractures. The benefits of an intervention protocol for post-menopausal women with strengthening exercises of the spine extensors, avoiding the main consequences of osteoporosis, which are thoracic kyphosis, vertebral fractures, height loss, and pain in the anterior chest (PFEIFER et al, 2004). Thus, physically active individuals tend to have less pain than sedentary ones.

The experimental limitations of this study include aspects related to the intensity of the class that was monitored by the Borg scale (Perceived exertion). The use of this scale requires attention due to the liability, since the construction was based on other physiological parameter, heart rate, which is sensitivity to individual's extrinsic and intrinsic factors (GONCALVES, 2008). However, according to Kruel and Graef (2006), the Borg scale still represents a practical and low-cost indicator especially when working in groups, allowing a match between the indexes obtained in and out of the water environment, in the same effort intensity.

\section{Conclusion}

The high-intensity aquatic exercise protocol proved to be effective for the exercised groups, benefiting postmenopausal women with and without fractures. The protocol provided increments in the BMD and T-score of the femoral head for those with fractures. In women without fractures, exercise acted as a protective factor for the occurrence of fractures due to the increased spine extension strength, and decreased pain perception and improvements of flexibility and neuromuscular variables. The intervention was safe for the spine even with the presence of fractures.

\section{References}


[1] AY, A.; YURTKURAN, M. Influence of aquatic and weightbearing exercises on quantitative ultrasound variables in postmenopausal women. American JournalofPhysical Medicine \& Rehabilitation. v.84, p. 52-61, 2005.

[2] BORG, G. Borg's perceived exertion and pain scales. Champaign: Human Kinetics, 1998.

[3] BROWN, JP.; JOSSE, RG. Clinical practice guidelines for the diagnosis and management of osteoporosis in Canada. Canadian Medical Association Journal. v.167, s. S1-S34. (10 suppl), november. 12, 2002

[4] DIXON,WG. LUNT,M; PYE, SR; REEVE,J; FELSENBERG,D;SILMAN,AJ; O'NEILL,TW. Low grip strength is associated with bone mineral density and vertebral fracture in women. Rheumatology. v.44, p.642-646, 2005.

[5] DOO, TH; SHIN,DA; KIM,HI; SHIN,DG; KIM, HJ; CHUNG,JH; LEE,JO. Clinical Relevance of Pain Patterns in Osteoporotic Vertebral Compression Fractures.JournalofKorean Medical Science. v. 23, p. 1005-10, 2008.

[6] GENANT, HK. WU, CY; VAN KUIJK, C; NEVITT, MC. Vertebral fracture assessment using a semiquantitativetechnique. Journal of bone and mineral research. v.8, n. 9, 1993.

[7] GONÇALVES,I. Esforço máximo e supramáximo na hidroginástica. Caracterização e avaliação do risco cardiovascular. Porto: Dissertação de licenciatura apresentada a Faculdade de Desportos da Universidade do Porto.2008.158p

[8] HAMILTON, C. J.; SWAN, V. J. D.; JAMAL, S. A. The effects of exercise and physical activity participation on bone mass and geometry in postmenopausal women: a systematic review of pQCT studies. OsteoporosisInternational. v. 21, p. 11-23, 2010.

[9] HUSKISSON EC: Measurement of pain. Lancet 2, p. 1127-31, 1974.

[10] HUNTER, G. R.; McCARTHY, J. P.; BAMMAN, M.M. Effects of resistance training on older adults. Sports Medicine, v.34, n.5, p.329-348, 2004.

[11] IBGE. O perfil dos idosos responsáveis pelos domicílios no Brasil 2000. Rio de Janeiro, 2002.

[12] LAZARETTI-CASTRO, M ; EIS, SR ; MARQUES NETO, JF . A prevenção da osteoporose levada a sério: uma necessidade nacional. Arquivos Brasileiros de Endocrinologia e Metabologia, v. 52, p. 712-713, 2008.

[13] LEWIECKI, E. M.; LASTER, A. J. Clinical Applications of Vertebral Fracture Assessment by Dual-Energy X-Ray Absorptiometry.TheJournalofClinicalEndocrinology\&Metabolis m. v. 91, n. 11, p. 4215-4222, 2006.

[14] KHAZZANI, H, ALLALI,F;BENNANI,L; ICHCHOU,L, EL MANSOURI,L; ABOURAZZAK, FE;REDOUANE ABOUQAL, R;HAJJAJ-HASSOUN, N. The relationship between physical performance measures, bone mineral density, falls, and the risk of peripheral fracture: a cross-sectional analysis.BMCpublichealth, v.9, p. 297, 2009

[15] KEMMLER,W. LAUBER D, WEINECK J, HENSEN J, KALENDER W, ENGELKE K.Benefits of 2 years of intense exercise on bone density, physical fitness, and blood lipids in early postmenopausal osteopenic women. Archivesinternationalofmedicine,v. 164,p. 1084-91, 2004.
[16] KRUEL,LFM; GRAEF,FI. Frequiência cardíaca e percepção subjetiva do esforço no meio aquático: diferenças em relação ao meio terrestre e aplicações na prescrição do exercício - uma revisão. RevistaBrasileira de Medicina do Esporte, v. 12, n. 4, 2006.

[17] MIYAKOSHI, N.; HONGO, M.; MAEKAWA, S.; ISHIKAWA, Y.; SHIMADA, Y.; ITOI, E. Back extensor strength and lumbar spinal mobility are predictors of quality of life in patients with postmenopausal osteoporosis. Osteoporosis International. v. 18, p. 1397-1403, 2007

[18] .NARCISO, FV; SANTOS,SS; FERREIRA,F;LEMOS,VS; BARAUNA,MA; CHEIK,NA. CANTO,RST.Altura percentual do centro de gravidade e número de quedas em idosos ativos e sedentários.Revista brasileira de cineantropomometria e desempenho humano. v.12, n.4, p. 302-307, 2010.

[19] NATIONAL OSTEOPOROSIS FOUNDATION (NOF). Clinician's Guide to Prevention and Treatment of Osteoporosis. Washington. NOF, 2008.

[20] NATIONAL INSTITUTE OF HEALTH CONSENSUS STATEMENT ONLINE.Osteoporosis Prevention, Diagnosis, and Therapy.March p. 27-29; [11/10/2009]; v.17(1): 1-36, 2000

[21] PFEIFER, M; SINAKI, M; GEUSENS, P; BOONEN, S; PREISINGER, E; MINNE. Musculoskeletal Rehabilitation in Osteoporosis: A Review.Journal of Bone and Mineral Research. v 19, n. 8,2004

[22] SINAKI, M; BREY, E. R. H.; HUGHES, C. A.; LARSON, D. R.; KENTON R. KAUFMAN Balance disorder and increased risk of falls in osteoporosis and kyphosis: significance of kyphotic posture and muscle strength. OsteoporosisInternational. v. 16, p. 1004-1010, 2005.

[23] SINAKI, M. The Role of Physical Activity in Bone Health: A New Hypothesis to Reduce Risk of Vertebral Fracture. Physical Medicine and Rehabilitation Clinics of North America. v. 18, p. 593-608, 2007.

[24] SINAKI, M. PFEIFER, M; PREISINGER, E; ITOI, E, RIZZOLI R, BOONEN,S, GEUSENS P, MINNE, HW.The Role of Exercise in the Treatment of Osteoporosis. Current Osteoporosis Reports. v. 8, p. 138-144, 2010.

[25] SMITS-ENGELSMAN, BCM.; BEKKERING, GE; HENDRIKS,HJM. Clinical practice guidelines for physical therapy in patients with osteoporosis. KNGF-guidelines for physical therapy in patients with osteoporosis. v. 05, 2003.

[26] TIDEIKSAAR, R. Falls in older people: Prevention and management. Baltimore, MD: Health Professions Press. p.15, 2002.

[27] TOLOMIO, S; ERMOLAO, A; LALLI, A; ZACCARIA,M et al. The Effect of a Multicomponent Dual-Modality Exercise Program Targeting Osteoporosis on Bone Health Status and Physical Function Capacity of Postmenopausal Women. JournalofWomen\&Aging. v. 22, n. 4, p. 241-254, 2010.

[28] WELLS KF, DILLON EK. The sit and reach: a test of back and leg flexibility. ResearchQuarterly for Exercise\&Sport, v 23 p.1158,1952

[29] WILDER, RP.; BRENNAN, D.; SCHOTTE, D. E. A standard measure for exercise prescription for aqua running. American Journalof Sports Medicine, Baltimore, v. 21, p.45-48, 1993. 